\title{
Use of Local Materials In The Preservation of Garcinia Kola (Bitter Kola) Seeds
}

\author{
Ajayi S., Eyong O. O. \\ Department of Forestry and Wildlife management, Cross River University of Technology (CRUTECH), (Obubra campus), \\ P.M.B 102, Obubra, Cross River State, Nigeria
}

\begin{abstract}
Storage of Bitter kola (Garcinia kola) was carried out using different local materials to evaluate the most appropriate storage material relative to the extension of its shelf life. The materials were kept moist by wetting them throughout the period of study ( 8 weeks). The local materials used were sandy soil, jute bag, clay pot and Plantain leaves. Three different parameters were used to assess the effectiveness of these local materials. The parameters were weight loss, colour change and shrinkage.Colour and shrinkage were evaluated visually. For weight loss, storage materials were significantly different ( $p<0.05)$. Sandy soil and jute bag were observed to reduce weight loss $(27 g$ and $28.3 g)$ respectively than the other two (36.3g and 50g) for clay pot and plantain leaves respectively. Observation showed that seeds preserved in plantain leaves and jute bag maintained their initial brown colour after 8 weeks while those in sandy soil and clay pot were darker. None of the seeds preserved using sandy soil shrank, only two seeds from jute bag shrank but shrinkage was conspicuous on seeds from clay pot and plantain leaves. Generally, sandy soil and jute bags were regarded as the best local materials to preserve G. kola seeds.
\end{abstract}

Keywords-Bittercola, jute bag, clay pot, sandy soil, storage, shrinkage.

\section{INTRODUCTION}

G. kola commonly known as bitter kola, this medium sized tree is easily recognized by its finely hairy flowers and large fruits, the size and colour of an orange. Many tribes have different ways of calling it example Yoruba: Orogbo, Benin: Edun, Ijaw: Okan, Ibo: Adi, Efik: Efiari, Boki: Ojie and Ibibio: Efiat. The tree mostly about $40 \mathrm{ft}$ high in the under storey, sometimes reaching 90ft with a spreading crown, bole straight, bark brownish, smooth, slash thick, brown yielding the usual yellow juice. (Keay, 1989).

It is an indigenous medicinal tree belonging to the family of Clusiaceae formerly Gultiferae. It is mostly found in Central and Western Africa. As a tropical fruit tree species, it is characterized by slow rate of growth. It grows as a medium sized tree up to $12 \mathrm{~m}$ high and $1.5 \mathrm{~m}$ wide. According to Adegoke (1998), it has been shown to posses a caloric value of $35.8 \mathrm{kcal} / \mathrm{g}$. The fruits are normally harvested from July - October. A mature fruit tree produces 85 to 1,717 fruits, with 208 to 6,112 annually, having mean values of 834 fruits and 2,627 nuts per tree. It produces 26 tones/ha/annum, with 278 trees/ha at $6 \mathrm{~m} \times 6 \mathrm{~m}$ spacing. The fruit is reddish-yellow and seeds contain $10 \%$ carbohydrates, $5 \%$ crude protein and $>10 \%$ crude fats and sodium 215.10ppm (Seed Information Data Base, 2004). The fruit is about $6.25 \mathrm{~cm}$ in diameter and each fruit contains two to fourbrown seeds embedded in an orange coloured pulp .

Factors that discouraged farmers from growing G. kola include difficulties encountered in raising seedlings in nurseries and long gestation period before flowering and fruiting. However, many of the germination difficulties have been overcome by methods developed by Okafor (1998); Gyimah (2000) and Ajayi and Echi (2016). The extracts from seed and dry powdered seeds have been made into various forms, such as tablets, cream and tooth paste. G. kola was initially consumed as a stimulant before the remarkable bioactivities were explored. The stems and twigs of the plants are used as chewing sticks in many parts of Africa. It has been commercialized for years in major cities and has offered natural dental care to human (Onukwo et al, 2004).

Experimentations using G. kola kernels as hop substitutes in several indigenous alcoholic drinks, as well as flavor enhancer in the beverage industry also exist (FDA, 1999). Ofor et al, (2004) identified several ethno-botanical uses to which the indigenes of Imo State, Nigeria, put the $G$. kola seeds. These include as an antidote to snake bites, poison and over dose. They are used as snake repellents. For cough, vomiting etc.

G. kola is a medicinal plant which is exclusively tropical in distribution (Ajayi and Echi, 2016). Traditionally, African medicine regards the plant in high esteem. It is cultivated throughout West Africa for its edible fruit and seeds. It flowers between December to January. Its fruits and seeds are normally harvested annually between Julys to October, which make it a highly seasonal produce. The fruits are reddish yellow, about $2.5 \mathrm{c}$ in diameter, containing 2 to 4 brown seeds embedded in an orange colored pulp. Both pulp and seeds are edible. According 
to a report from the Centre for International Forestry Research, G. kola trade is still important to the tribes and villages in Nigeria. As with many herbs, never consume G. kola without first discussing its use and benefit with our physician, especially if you are currently being treated for other medical conditions.

G. kola fruits and seeds are normally harvested annually between July and October, which makes it a highly seasonal produce. There is evidence of mounting pressure on most Non-Timber Forest Products (NTFP's) which include G. kola (Ruiz-Perez, 1999). The predominantly traditional substinence land use system in Nigeria, coupled with the fast depleting reserve of important NTFP's like G. kola (bitter kola) in our forest, makes it imperative to increase the search for good preservation method of these valuable seeds. G. kola (bitter kola) seeds do not keep long after extraction and processing. After a week or two, if not properly preserved, the seeds begin to dry and thereby lose weight and value. In the past, efforts have been made to preserve G. kola (bitter kola) seeds using polythene bag sheets, tendered plantain leaves, dry plantain leaves and burying the seeds in the ground. However, there is no documented information as to the effectiveness of these materials for storing bitter kola.

It therefore becomes important to research into using these methods; to see which of them is the best for prolonging the shelf life of the seeds of $G$. kola (bitter kola) after harvesting.
The research determined weight loss, change in clour and level of shrinkage of garcinia cola using sandy soil, earth pot, plantain leaves and sack bag as preservation materials for eight (8) weeks.

\section{MATERIALS AND METHODS}

The experiment was carried out in the laboratory of the Department of Forestry and Wildlife Management, Cross River University of Technology, Obubra campus. Obubra Local Government Area lies between longitude $8^{\circ} 15^{\prime}$ East and Latitude $6^{\circ}$ North (see Figure 1).

Ripe fruits of G. kola was collected from a homestead garden in Adun community, Obubra Local Government Area of Cross River State. The seeds was collected and washed. The materials used include; sandy soil, clay pot, plantain leaves and sack bag.

A completely randomized design (CRD) was used for the study. Ten (10) seeds were assigned to each storage material (sandy soil, earth pot, plantain leaves and jute bags). The experiment was replicated three times. Initial fresh weight of seeds in each storage material was taken. Subsequently, a weekly assessment of their weight was carried out for two months, to determine loss of moisture during the storage period. Test was carried out after every four weeks to assess the quality of the seeds, in terms of color change and shrinkage. 

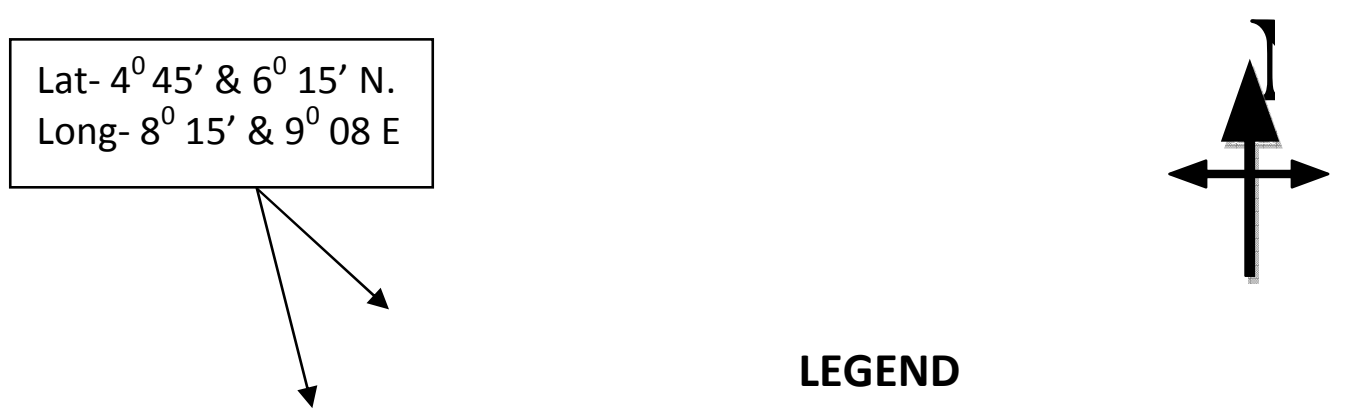

\section{LEGEND}

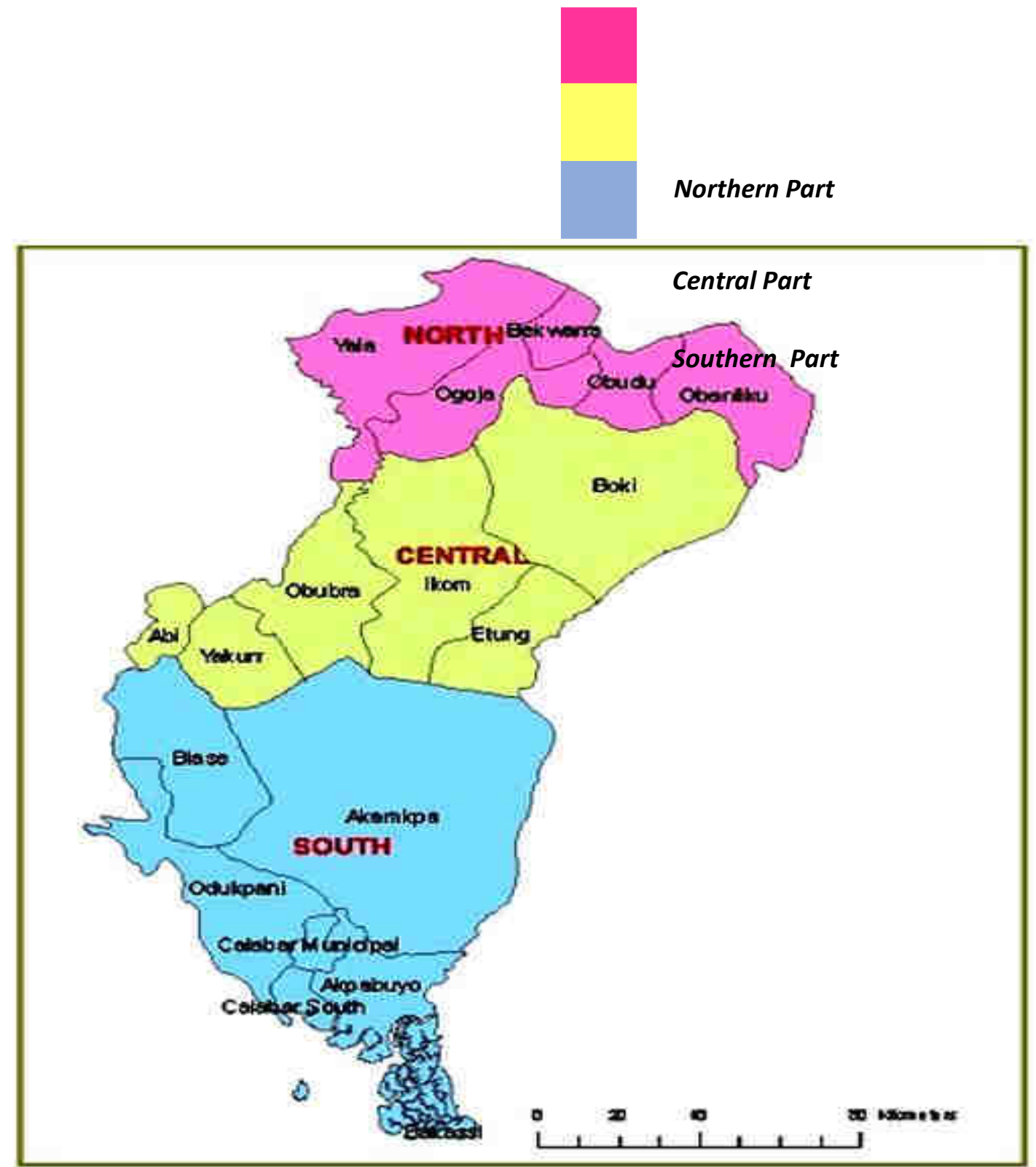

Fig. 1: Map of Cross River State Showing Obubra Local Government Area.

The mean annual rainfall is $2172.5 \mathrm{~mm}$ and the mean annual temperature is about $18^{\circ} \mathrm{C}$ to $32^{\circ} \mathrm{C}$.

Record of weight loss $(\mathrm{g})$ for each storage material was obtained after two weeks interval. Color and shrinkage of bitter kola by storage materials were observed and assessed virtually.

One - way Analysis of Variance was used to test for significant difference in the weight loss of bitter kola 
from the storage methods. Table was used to present the color change while bar chart was used to present shrinkage according to storage methods.

\section{RESULTS}

The result of the fresh weight assessment for eight weeks is presented in Table 1. The results shows that the storage of $G$. kola with the four local materials (treatments) were significantly different at $5 \%$ level of probability i.e. the different treatments used to preserve $G$. kola had an effect on its weight loss. Weight loss of $G$. kola was more in seeds preserved with plantain leaves followed by those in clay pot, then jute bag and finally sandy soil.

Results on the colour of seeds of G. kola preserved for 8 weeks (table 2) showed that seeds preserved in plantain leaves and jute bag retained their initial colour i.e. seeds preserved in plantain leaves and jute bag were brown in colour and retained its brown colour after 8 weeks. However, seeds in sandy soil and clay pot turned dark and dark brown respectively from their initial brown colour. The multiple bar chart (figure 1) shows the frequency of the seeds that shrank and those that did not shrink for each treatment.

Table 1: Analysis of variance (ANOVA) for Weight Loss of $G$. kola Seeds.

\begin{tabular}{|c|c|c|c|c|c|}
\hline $\begin{array}{c}\text { Source of } \\
\text { Variation } \\
(\mathbf{S V})\end{array}$ & $\begin{array}{c}\text { Sum of } \\
\text { Squares } \\
(\text { SS })\end{array}$ & $\begin{array}{c}\text { Degree } \\
\text { of } \\
\text { Freedom } \\
\text { (DF) }\end{array}$ & $\begin{array}{c}\text { Mean } \\
\text { Square } \\
(\text { MS) }\end{array}$ & $\begin{array}{c}\text { F- } \\
\text { value }\end{array}$ & Sig. \\
\hline Treatment & 1020.667 & 3 & 340.222 & 35.813 & $* * *$ \\
\hline Error & 67.000 & 8 & 9.500 & & \\
\hline Total & 1096.667 & 11 & & & \\
\hline
\end{tabular}

\begin{tabular}{|c|c|c|c|c|}
\hline \multirow{2}{*}{ TREATMENT } & \multirow{2}{*}{$\mathrm{N}$} & \multicolumn{3}{|c|}{ Subset for alpha $=0.05$} \\
\cline { 3 - 5 } & & 1 & 2 & 3 \\
\hline Sandy Soil & 3 & $\begin{array}{c}26.67 \pm 0 . \\
58^{\mathrm{d}} \\
28.33 \pm 0 . \\
58^{\mathrm{c}}\end{array}$ & & \\
Jute Bag & 3 & & $36.33 \pm 0$. & \\
Clay Pot & 3 & & $58^{\mathrm{b}}$ & \\
Plantain leaves & 3 & & & $50.00 \pm 6$. \\
Sig. & & .526 & 1.000 & $08^{\mathrm{a}}$ \\
& & & 1.000 \\
\hline
\end{tabular}

Means for groups in homogeneous subsets are displayed.

Table 2: Colour observation of seeds of G. kola.

\begin{tabular}{|c|c|c|c|}
\hline $\begin{array}{c}\text { Storage } \\
\text { Material }\end{array}$ & Initial & $\begin{array}{c}\text { Colour } \\
\text { After } \\
\text { Colour }\end{array}$ & $\begin{array}{c}\text { Colour } \\
\text { After Two } \\
\text { Months }\end{array}$ \\
\hline
\end{tabular}

\begin{tabular}{|c|c|c|c|}
\hline & Month & \\
\hline Sandy soil & Brown & Brown & Dark \\
\hline Clay pot & Brown & Brown & $\begin{array}{c}\text { Dark } \\
\text { Brown }\end{array}$ \\
\hline $\begin{array}{c}\text { Plantain } \\
\text { Leaves }\end{array}$ & Brown & Brown & Brown \\
\hline Jute bag & Brown & Brown & Brown \\
\hline
\end{tabular}

Source: Field study, 2016.

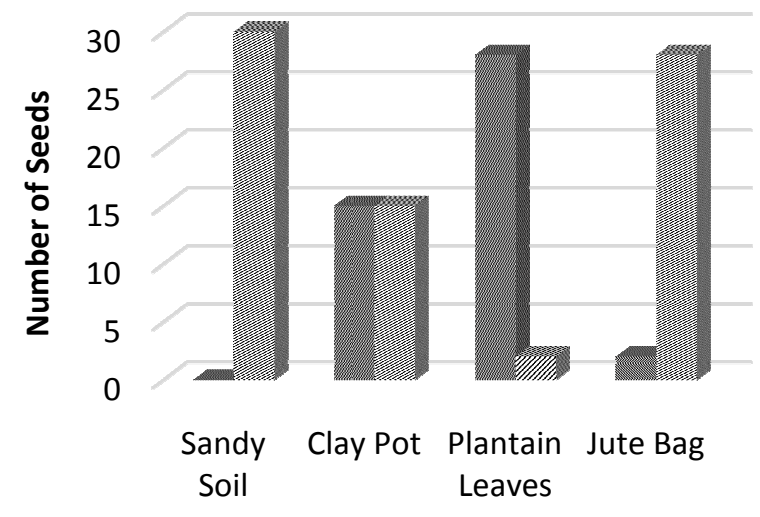

Storage Materials

\section{\#SHRINK जUNSHRINK}

Fig.1: Shrinkage of G. kola seeds.

It shows that none of the seeds preserved in sandy soil shrank. In ranking according to the number of seeds that did not show shrinkage per treatment, jute bag is next to sandy soil as only two out of the thirty seeds shrank. An equal distribution of shrinkage was observed in seeds preserved using clay pot (15 shrank and 15 did not). Seeds preserved using plantain leaves showed a high level of shrinkage; only two G. kola seeds out of the thirty seeds used to carry out this experiment did not shrink.

\section{DISCUSSION}

Seeds preserved in sandy soil and jute bag are considered to be first and second best respectively. G. kola seeds before preservation can be seen in plate 1 .

Similar studies carried out by Korie (1996), on the effect of packaging materials on Cola nitida, confirmed the keeping ability of polyethelene bags over other methods of packaging used.

This study has shown that although seeds preserved using jute bags (plate 2) are not considered the best in terms of retaining moisture content of $G$. kola seeds, it is a good way of preserving them especially for a short period of time. 
Seeds preserved in plantain leaves were observed to be the biggest losers of weight (moisture). This finding is not far from that of Opeke (1987) that various parasitic fungi developed during the storage of kola nuts, as a result of high transpiration rate within the storage baskets with dry plantain leaves (plate 3 ).

The colour of G. kola seeds can be said to be a major consideration during purchase in terms of its attractiveness and palatability. The results show that after four weeks of storage, all four treatments used to preserve G. kola seeds maintained their initial colour (brown). However after 8 weeks, seeds preserved using sandy soil and clay pot (plate 4) were observed to have a colour change from brown to dark and dark brown respectively. In comparison with the weight loss observed in this seeds, a little discrepancy was observed.

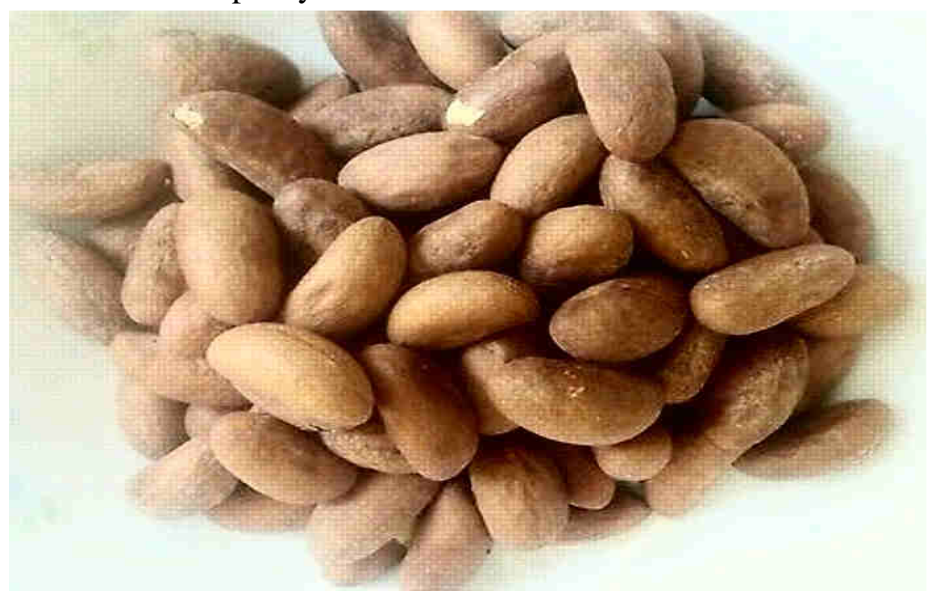

Plate 1:G. kola seeds before preservation.

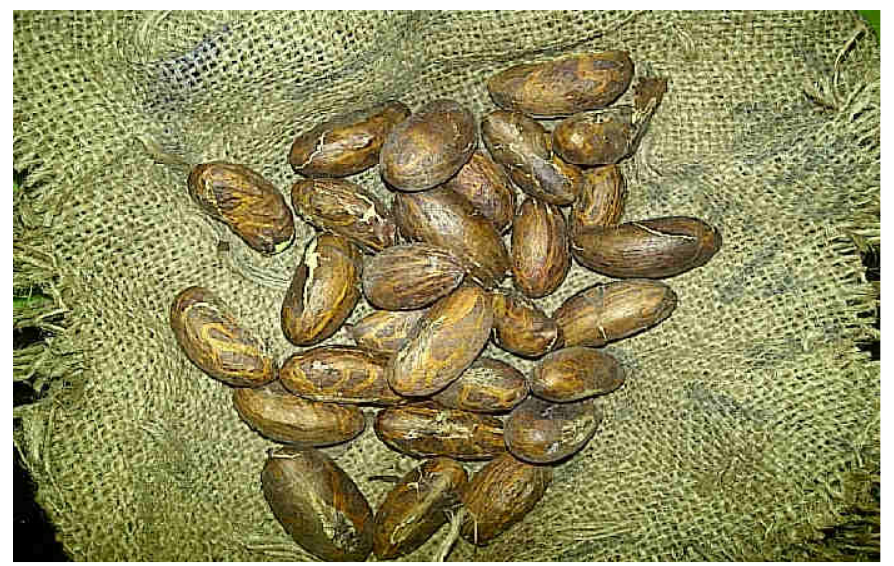

Plate 2:G. kola seeds preserved using jute bag.

Although, seeds preserved in jute bags that was ranked second in terms of its ability to preserve moisture also was observed to retain its normal brown colour after 8 weeks, seeds preserved using sandy soil (plate 5) that was ranked first in term of moisture conservation were observed be darker than its normal brown colour which could alter its market value.

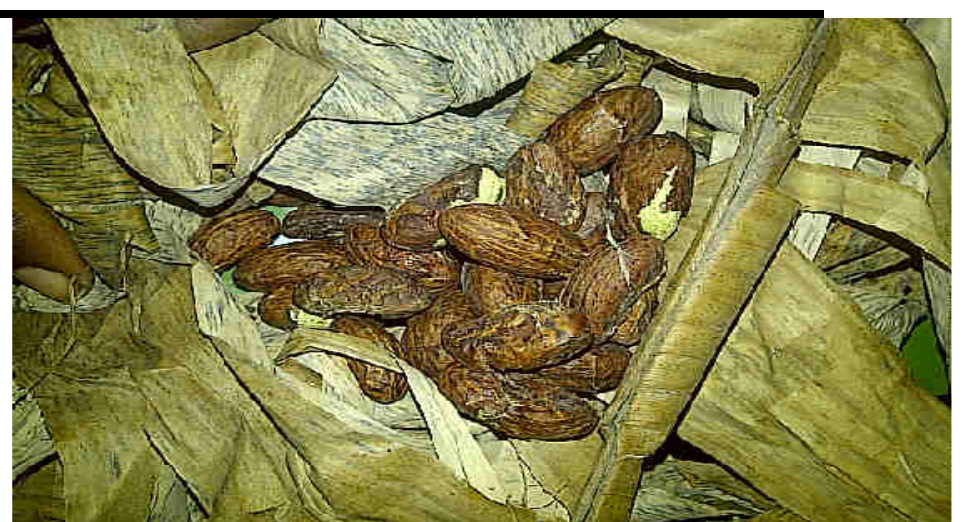

Plate 3:G. kola seeds preserved using plantain leaves.

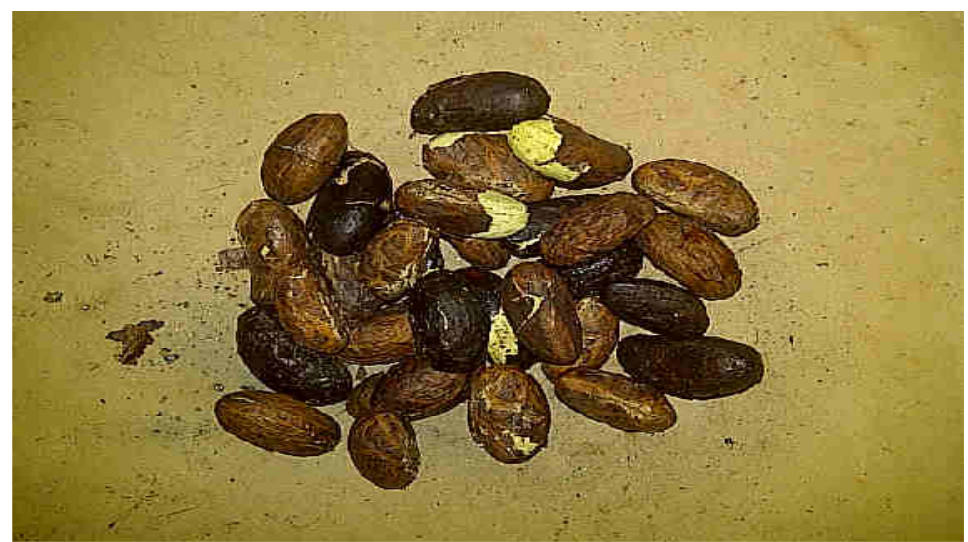

Plate 4:G. kola seeds preserved in clay pot.

Seed shrinkage is associated with loss of moisture i.e. the more the moisture content reduces, the more the seeds shrink. This is not a different situation as it is evident in this study that the treatment that shrank most is the treatment that lost the most weight (moisture) which according to the study was plantain leaves. According to Odebunmi et al., (2009), the moisture content in G. kola seeds consist of $66.40 \%$ and has a dry matter composition

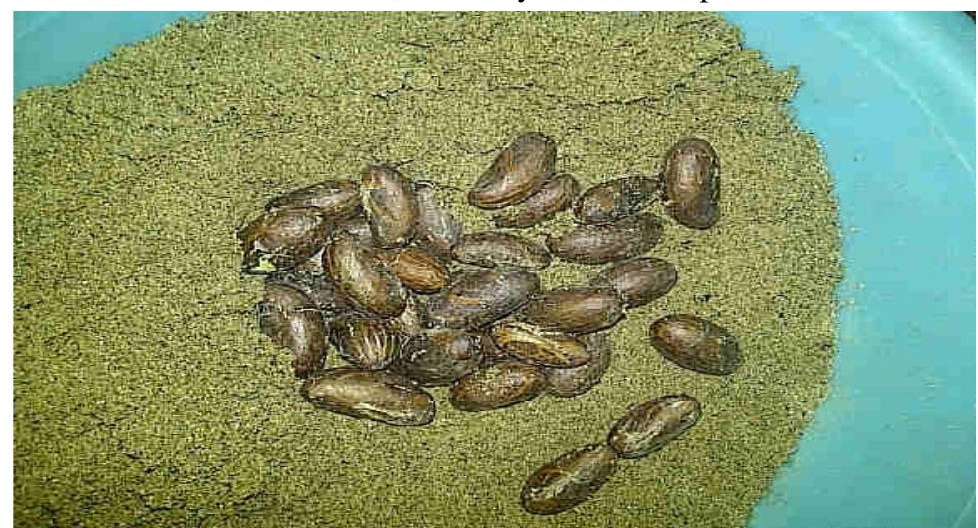

Plate 5:G. kola seeds preserved in sandy soil. of $33.6 \%$ of its total weight. As seen above, the moisture content of $G$. kola comprises more than half of its total composition, therefore a reduction in the moisture will be evident in the level of shrinkage. 


\section{CONCLUSION AND RECOMMENDATIONS}

Generally, results from the three parameters (weight loss, colour and shrinkage) used to assess the efficiency of the four different local materials showed that sandy soil is the best local material in preserving G. kola seeds (as it came first in weight loss and shrinkage and third in colour preservation), it is followed by jute bag which was the best in terms of colour preservation but came second in both weight loss and shrinkage. The use of plantain leaves to preserve $G$. kola was seen to be the worst method to adopt. Seeds preserved using plantain leaves lost weight most, and showed the shrinkage most (in terms of number), but however was one of the best treatment in terms of colour of seeds preservation. Consequently, the use of clay pot to preserve G. kola seeds is not a good option as the results showed that seeds preserved in clay pot came third both in weight assessment and shrinkage and last in colour preservation.

Based on the findings from this research, the following recommendations are made:

1. Sandy soil and jute bag should be used to preserve G. kola seeds.

2. Future research should also be carried out to evaluateother local materials for their sustainability in storing biter kola.

3. Palatability test should be included in future investigations.

\section{REFERENCES}

[1] Adegoke GO, Kumar MV, Sambaiah K, Lokesh BR (1998).Inhibitory effect of $G$. kola on lipid peroxidation in ratliver homogenate. Indian J. Exp. Biol., 36: 907-910.

[2] Ajayi, S. and Echi, A. A.(2016) Effectof Pregermination treatments on the dormancy breaking and early growth Performance of bitter kola (G. kola (Hechel) in South Southern Nigeria. Journal of Research in Forestry, Wildlife and Environment. 8(2) :29 - 39

[3] FDA (1999) FDA/CFSAN/OPA: Agency Response letter: GN 25 on the use of $G$. kola seeds in distribution.

[4] Keay, R. W(1989). Trees of Nigeria. Clarendon Press, Oxford. 1989. Pp.476.

[5] Korie, C.N. (1996). Effect of different packagingmaterials on the shelf-life of kola (Cola nitida). B. Agric. Tech. (Crop Production) Project Report, Federal University of Technology, Owerri. $62 \mathrm{pp}$.

[6] Odebunmi, E. O., Oluwaniyi, O. O., Awolola, G.V. and Adediji, O. D. (2009) Proximate and nutritional composition of kola nut (Cola nitida), bitter cola (Garcinia cola) and alligator pepper(Afromomum melegueta), African Journal of Biotechnology Vol. 8 (2), pp. 308-310.

[7] Ofor, M. O; Ngobili, C. A. and Nwufo, M. L. (2004). Ethno-botanical uses and trade characteristics of $G$. kola in Imo State Nigeria. International Journal of Agriculture and Rural Development 5: 140-144.

[8] Onunkwo, G. C H.C. Egeonu, M.U. Adiukwu J.E. Ojile, A.K. Oluwasulu (2004). Some physical properties of tabulated seed of G. kola (HECKEL). Chemical and pharmaceutical Bulletin (Tokyo) 52. Pp.649 - 53.

[9] Okafor, J.C. (1998). Mass propagation of species for immediate Utilization paper. Presented at the meeting of under utilized crops of Nigeria. 4-8 May. NACORAB moor plantation. Ibadan, Nigeria.

[10] Opeke, L. K. (1987). Tropical Tree crops. Spectrum Books Limited. Cited in Korie, C.N. (1996). Effect of different packagingmaterials on the shelf-life of kola (Cola nitida).

[11] Ruiz-Perez, M., Ndoye, O., Eyebe, A. and Lema, D. (1999). Women and the forest trade: gender analysis of Non-Wood Forest Products markets in the humid forest zone of Cameroon. Cited In: Ruiz- Perez et al. (1999). Marketing Non-Wood Forest Products in the humid forest of Cameroon. In: Dembner and Perlis (eds.) Unasylva No. 198. Nonwood forest product and income generation Vol. 50.

[12] Seed Information Data (SID).2004. Http://www.rbgkew.org.UK/Data/Sid. 